\title{
Research on the Physical Characteristics of the Elder People and Park Design
}

\author{
Yun-Ji Zhang, Yong-Ji Piao, Tae-Dong (Cho ${ }^{1 *^{*}}$ \\ Department College of Horticulture, Shandong Agricultural University, Tai'an 271018, PR China \\ ${ }^{1)}$ Department of Environmental Landscape Architecture, Gangneung-Wonju National University, \\ Gangneung 210-320, Korea \\ (Manuscript received 2 February, 2012; revised 23 February, 2012; accepted 15 May, 2012)
}

\begin{abstract}
This article reveals the relationship between the body characteristics of the elder people and the size of park facilities during utilization of parks by scientific investigation. The experiment involves 540 elder people, and offer concrete evidence for park design in ageing society. These evidences mainly consists of the following aspects: First, the relation between physical situation of elder people and their using parks. Secondly, the relation between the hearing status and exchange circle diameter in elders. The last is the relation between the distance visual acuity and designing the scene. Finally we get the most suitable step length range, stairs height, road slope, communication space diameter and general formulas about the best vision distance for elder people.
\end{abstract}

Key Words : Elder people, Physical characteristics, Parks design

\section{Introduction}

As a part of the social welfare facilities, the city park must service for all the people coming from a variety of stratums and with different ages. But now it considers the children, youth and middle age much more than the elder people. According to the investigating results of the satisfaction degree of the elderly in utilization of parks, there are only 39-61\% of the elderly who are satisfied with the quality of parks (Han, 2000; Piao, 2005).

Present investigating contents on the relationship between elderly individual attributes and their utilizing parks include sex, age, occupation, family constitution, distance, transportation tools, aim,

"Corresponding author : Tae-Dong Cho, Department of Environmental Landscape Architecture, Gangneung-Wonju National University, Gangneung 210-320, Korea

Phone: +82-33-640-2358

E-mail: aroma058@hanmail.net reason, frequency, content, companion, staying time, degree of satisfaction and so on(Han, 1999; Han, 2000; Piao, 2005).Due to increasing aging, elder people's physical functions tend to weaken(Zhang, 1987). This will directly lead to the size of park element being specially modified. So far there is no research about this field. This research is designed to cause concerns on park designing related to aging society and provide reliable data to parks designed for the elderly.

\section{Materials and Method}

Results show that in the process of using parks, the ratio of elder people of age 60-69, 70-79, 80-89 are $2: 3: 1$ and the ratio of men and woman is close to 1 : 1(Zhang, 2008). According to these we choose 540 healthy elder people of different age and different gender as investigation objects. The research is done by undergraduates and postgraduates of garden professional. 


\section{Results and Discussion}

3.1. Physical Situation of Elder people and Their Using Parks

\subsubsection{Footsteps Length Range}

On the flat ground, first, we let elder people walk 100 steps continuously as long as they can and take an average as the greatest footsteps; Then we let elder people walk 100 steps freely and take an average as the freely footsteps. The results are shown as follows:

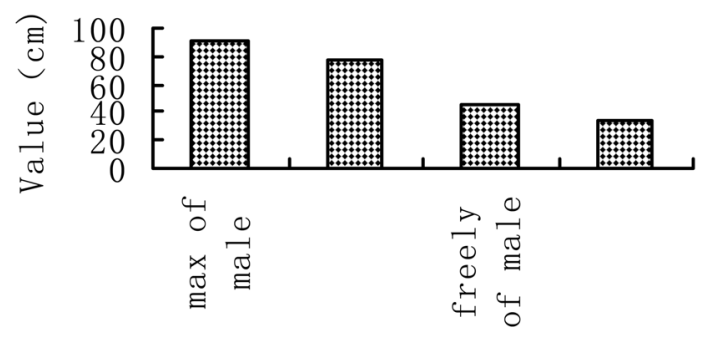

Category

Fig. 1. Step length of elder people.
For male elder people, the greatest footsteps are $90.15 \mathrm{~cm}$ and the freely footsteps are $44.92 \mathrm{~cm}$; for female elder people, the greatest footsteps are $74 \mathrm{~cm}$ and the freely footsteps are $33.62 \mathrm{~cm}$.

Therefore we should design steps; walking stones; plum stakes and others facilities relation on step length according to these steps. We can conclude that the most suitable step length is $35 \mathrm{~cm}$.

\subsubsection{Stair's Height}

When the widths of stairs are no more than freely steps length and heights are $15 \mathrm{~cm}, 17 \mathrm{~cm}, 19 \mathrm{~cm}, 21$ $\mathrm{cm}, 23 \mathrm{~cm}$, and let elder people step up on them continually for two steps, six steps and twelve steps. The number of steps is labeled as easy, moderate, sweat and difficult. The results are shown as follows:

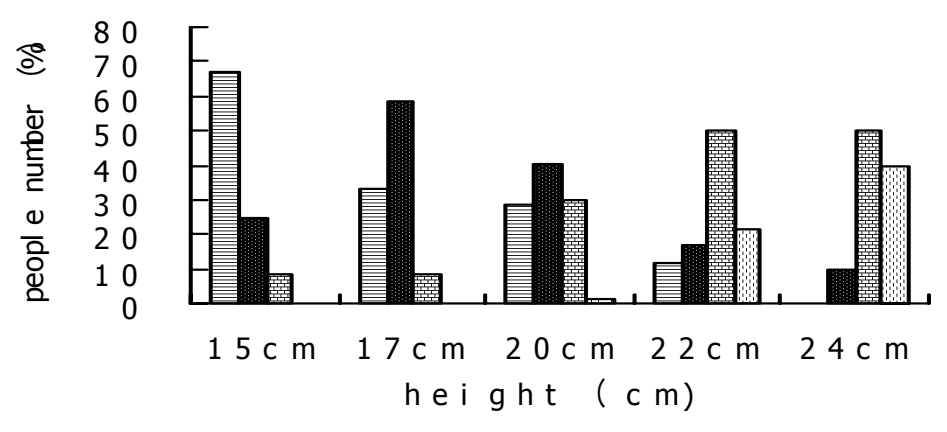

트를 e a y

moderat e

国 s we a t y

ifficult

Fig. 2. Situation of going up six stairs continually.

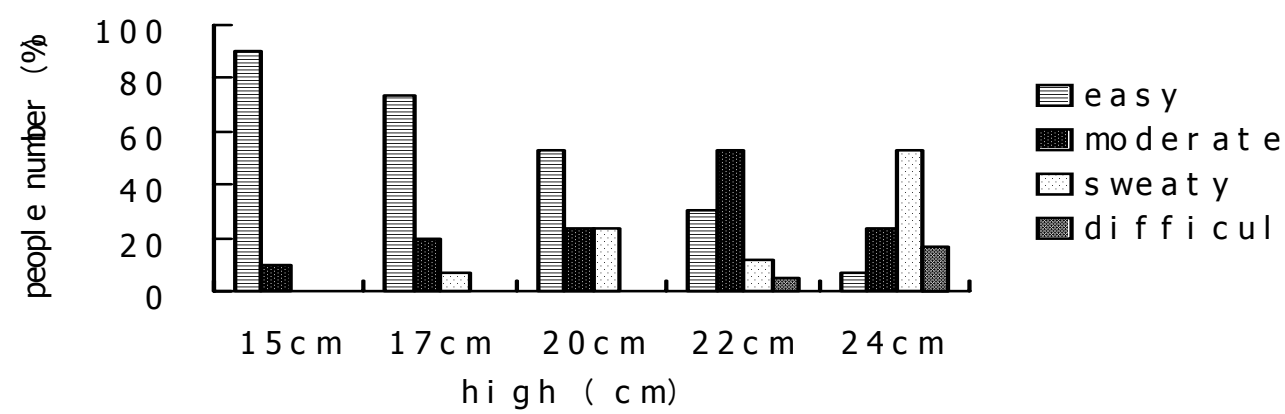

Fig. 3. Situation of going up twelve stairs continually. 
In the elder people going up two stairs continually case, the results are as follows: when the step height is $15 \mathrm{~cm}$, more than $90 \%$ of elder people feel easy; when the step height is $17 \mathrm{~cm}$, more than $70 \%$ of elder people feel moderate; when the step height is 22 $\mathrm{cm}$, nearly $50 \%$ of elder people feel moderate and more than $20 \%$ of elder people feel difficult; when the step height is $24 \mathrm{~cm}$, more than $70 \%$ of elder people feel sweat or difficult.

In the elder people going up six stairs continually case, the results are as follows: when the step height is $15 \mathrm{~cm}$, more than $70 \%$ of elder people feel easy; when the step height is $17 \mathrm{~cm}$, more than $60 \%$ elder people feel moderate; when the step height is $20 \mathrm{~cm}$, near $40 \%$ of elder people feel moderate and more than $30 \%$ of elder people feel sweat or difficult; when the step height is $22 \mathrm{~cm}$, more than $70 \%$ of elder people feel difficult; when the step height is $24 \mathrm{~cm}$, more than $90 \%$ of elder people feel sweat or difficult.

In the elder people going up twelve stairs continually case, the results are as follows: even if the step height is $15 \mathrm{~cm}$, near $30 \%$ of elder people feel difficult and need rest during the experiment.

Thus, in park design, if we set up the stairs less than two steps, its height should be $17 \mathrm{~cm}-22 \mathrm{~cm}$. If the stair has more than six steps, its height should be $15 \mathrm{~cm}-17 \mathrm{~cm}$ in order to fit elder people to use. If climbing distance requires more than 12 steps, we should provide separate stairs so that elder people may have a rest.

\subsubsection{Fatigue Distance}

According to the data, road slope for the disabled should not be more than 4\%; common road slope should be $12 \%$ and should not reach $18 \%$ ( Meng Zhao-Zhen, 1996). Therefore, we do experiment and calculate the fatigue distance of the elder people when they walk freely on the road with slope of $2 \%$, $4 \%, 8 \%, 12 \%, 18 \%$ and get results as follows:

Results show that when the road slope fall below $2 \%$, the average fatigue distance of elder people is $498.2 \mathrm{~m}-251.2 \mathrm{~m}$; when the road slope is $4 \%$, it is $245.53 \mathrm{~m}-76.34 \mathrm{~m}$; when the road slope is $8 \%$, it is $76.32 \mathrm{~m}-38.21 \mathrm{~m}$; when the road slope is $12 \%$, it is $41.17 \mathrm{~m}-20.08 \mathrm{~m}$ and when the road slope is $18 \%$, it is $26.38 \mathrm{~m}-10.26 \mathrm{~m}$.

Therefore, we propose that if the road has a relatively small slope we should set rest facilities every ten meters. If the road slope is $4 \%, 8 \%, 12 \%$ and $18 \%$, we should set rest facilities every $70 \mathrm{~m}, 35$ $\mathrm{m}, 20 \mathrm{~m}$, and $10 \mathrm{~m}$ so that the elder people would not feel tired when they using parks.

In the mean time, we find that when the road slope reaches to $8 \%$, the fatigue distance of elder people shorten obviously. This tells us that the road slope should be less than $8 \%$ in order that elder people feel comfortable when they walk in parks.

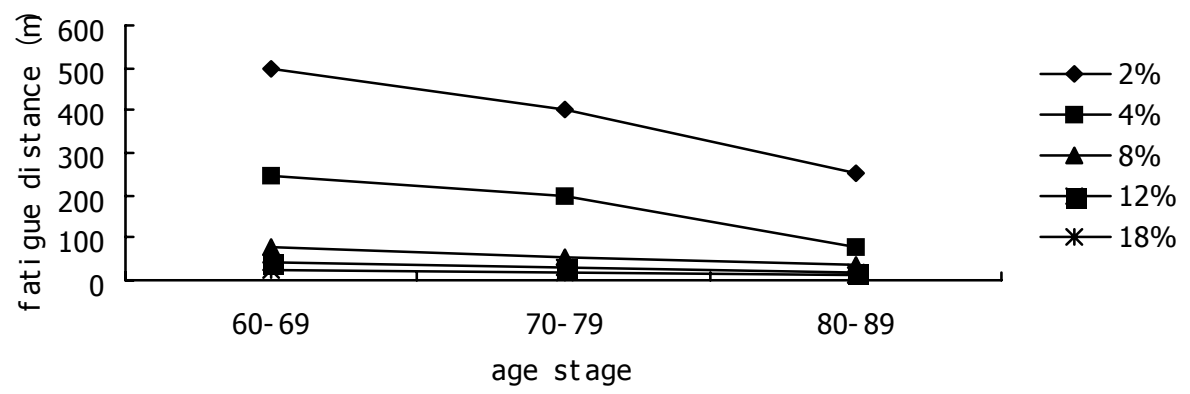

Fig.4. fatigue distance of elder people. 


\subsection{Hearing and Exchange Circle Diameter}

According to international findings(Xu, 1988), hearing damage of elder people starts from Middle-aged and fall rapidly after 60 years old. According domestic reports(Cooperation Study Group of China and America Education of Medical, 1988), more than $50 \%$ of elder people have different degree of hearing failing.

Thus, we design an experiment that in a relatively quiet outside environment we let the elder people communicate with each other at a distance of $1 \mathrm{~m}-10 \mathrm{~m}$ meters. We get results as follows:

In a relatively quiet outside environment, within 2 m apart, nearly $100 \%$ of elder people (except one person whose hearing hurt seriously) are able to communicate with each other easily; exchange begins to become difficult from $3 \mathrm{~m}$. Within $5 \mathrm{~m}$ apart, more than $80 \%$ of elder people can communicate with each other normally; within 7 m meters apart, nearly $20 \%$ of elder people are not able to communicate with each other normally; above $9 \mathrm{~m}$ apart, more than $35 \%$ of elder people can not communicate at all.

Thus, we conclude that the best communication space diameter for elder people is $3 \mathrm{~m}$ and no more than $7 \mathrm{~m}$. Stool should be placed around in order that elder people could see and understand each other by gesture when they can not hear clearly.

\subsection{Vision and Designing the Scene}

$80 \%$ of elder people's perception of information in parks is through vision(Xu, 1988). Vision obviously decreases with age. According to the investigation, $72.97 \%$ of the 400 people whose vision fall below 0.05 are elder people. ( 0.05 is the legal standard of blind all over the world)(Kermis, 1984). In view of this we have a test as follows:

\subsubsection{Range of Visibility and Watching Place} Vertical Watching:

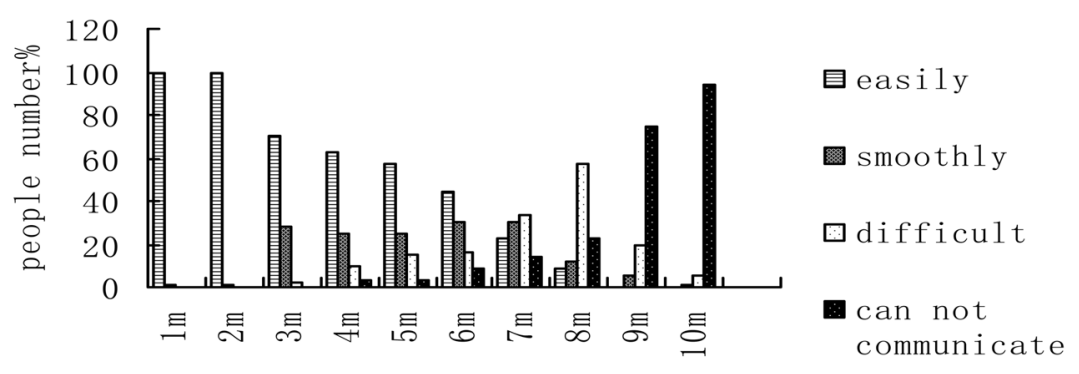

diameter (m)

Fig. 5. hearing of elder people.
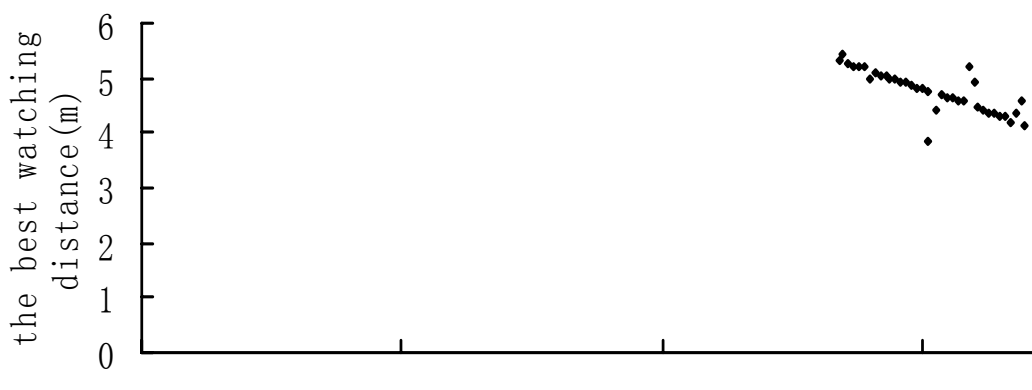

Fig. 6. vertical vision distance of elder people. 
First, in $30^{\circ}$ space range, which is the best vertical vision space range, we let elder people watch the same sculpture $(\mathrm{H}=3 \mathrm{~m})$ and find the best watching distance. Then we measure eyes height above the ground level and establish a coordinate system. Last, we make scattered points graph and analysis as follows:

Horizontal Watching:

Scattered points show the relationship between eyes height and the best watching distance is linear. We let the vision distance coefficient is $\mathrm{K}$ and get formula just as $\mathrm{y}=\mathrm{k}(\mathrm{H}-\mathrm{x})$. Through calculation we get $\mathrm{k}_{\text {vertical }} \approx 3.22$.

In $45^{\circ}$ space range, which is the best horizontal vision space range, we let the elder people watch 16 flower belts ( $2 \mathrm{~m}-5 \mathrm{~m}$ length) and find the best watching distance. Then we establish a coordinate system and make scattered points graph as follows:

We let the vision distance coefficient is $\mathrm{K}$ and get formula just as $y_{n}=k_{n} x$. Through calculation we get $k$ horizontal $\approx 1.06$.

According to these, we get a general formula about the best vision distance for elder people as follows:

(1) In $30^{\circ}$ vertical vision space range: $\mathrm{L} \approx 3.22(\mathrm{H}-\mathrm{h})$

(2) In $45^{\circ}$ horizontal vision space range: $\mathrm{L} \approx 1.06 \mathrm{~W}$

$\mathrm{L}$ — the best vision distance $(\mathrm{m})$

$\mathrm{H} \_$objects height watched by elder people(m)

$\mathrm{h}$-_eyes height above the ground level(average is $1.39 \mathrm{~m}$ )

W-_objects width watched by elder people(m)
The best vision distance coefficient for the general population, which includes children, adolescents, and adults, is 3.7 and 1.2. Comparing to the elder people's best vision distance coefficient, we find that the elder people vision distance is obviously shorten. So we should set watching places in front of sceneries according to these formulas and set chairs or flower shelves in these places so that elder people could watch them there.

\section{Conclusion}

1) The most suitable step length range for elder people is $39.27 \mathrm{~cm}-74 \mathrm{~cm}$.

2) If a park needs to set up stairs that are less than two steps, its height should be $17 \mathrm{~cm}-22 \mathrm{~cm}$. If a park needs to set up the stairs are more than six steps, its height should be $15 \mathrm{~cm}-17 \mathrm{~cm}$ in order to fit the elder people to use. If a park needs to set up the stairs more than twelve steps, we should set flat part in half so that elder people may have a rest there.

3) If the road is almost flat, we should set rest facilities every $10 \mathrm{~m}$; If the road slope is $4 \%, 8 \%$, $12 \%$ and $18 \%$ we should set rest facilities or smooth part every $70 \mathrm{~m}, 35 \mathrm{~m}, 20 \mathrm{~m}$ and $10 \mathrm{~m}$ for elder people to have a rest in half.

4) The best communication space diameter for elder people is $3 \mathrm{~m}$.

5) General formulas about the best vision distance for elder people are as follows:

$$
\mathrm{L}_{\text {vertical } \approx 3.22(\mathrm{H}-\mathrm{h})}
$$

$\mathrm{L}_{\text {horizontal }} \approx 1.06 \mathrm{~W}$.

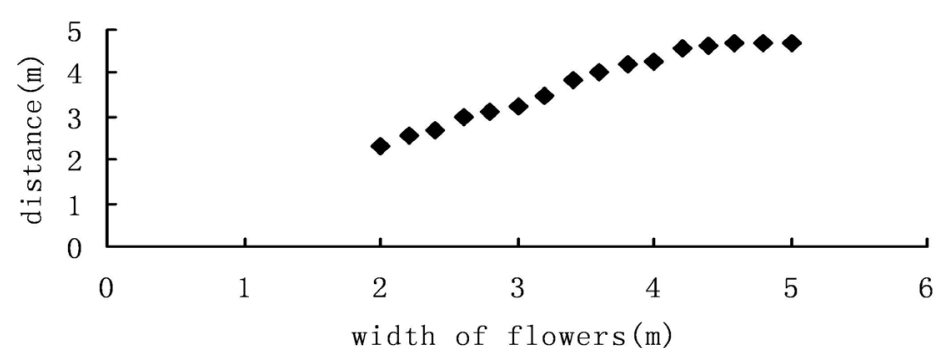

Fig. 7. horizontal vision distance of elder people. 


\section{Reference}

Cooperation Study Group of China and America Education of Medical, 1988, Survey Analysis on Listening Disabilities in elders of China and America, Chinese Mental Health, 1988.

Han, B. Y., 1999, Design of Park for Elderly, Guangdong Landscape Architecture, 20-22.

Han, B. Y., 2000, Design of Park for Elderly, Chinese Landscape Architecture, 16(2).

Kermis, M. D., 1984, the Psychology of Human Aging, Theory, Research, and Practice, Boston, Allyn and Bacon, Inc, 159-185.
Meng, Z. Z., 1996, Landscape Engineering, China Forestry Publishing House, The initial printing, 185-189.

Piao, Y. J., 2005, Comparison on Elderly Utilization in parks in China Japan and American, Chinese Landscape Architecture, 2005(8), 27-30.

$\mathrm{Xu}$, S. L., 1988, The Changes and repartee in The Vision, Hearing and Psychomotor Performance Reaction in Elders, Chinese Mental Health, 2(3), 136-140.

Zhang, W. T., 1987, Vision of Elders, Beijing Scientific Publishing House, 44-67.

Zhang, Y. J., 2008, Research on the Individual Attributes of Elder People in Utilization of Parks, Modern Landscape Architecture, 5, 22-26. 